\title{
Depression in patients who underwent enucleation or evisceration
}

\author{
Jirathip Luangrungrot ${ }^{1 *}$, Phanthipha Wongwai ${ }^{1}$, Suwanna Arunpongpaisal ${ }^{2}$, Sirinya Suwannaraj ${ }^{1}$ and Oracha Teerakapong $^{3}$ \\ ${ }^{1}$ Department of Ophthalmology, Faculty of Medicine, Khon Kaen University, Thailand \\ ${ }^{2}$ Department of Psychiatry, Faculty of Medicine, Khon Kaen University, Thailand \\ ${ }^{3}$ Department of Ophthalmology, Khon Kaen Hospital, Thailand
}

\begin{abstract}
Objective: To compare depression score between pre and post enucleation or evisceration. To measure health utility index of patient underwent enucleation or evisceration

Methods: 24 patients who were schedule to have enucleation/evisceration between June 2016 - January 2017 were included. KKU-DI screening questionnaire and EQ-5D-5L questionnaire were asked to complete at the day before surgery, 1-day post operation, 7 days post operation and 90 days post operation. General estimating equation was used to analysis the mean difference of depression score during each point of time.

Results: Median age is 60 years (Q1-Q3, 53-70), 20 patients (83\%) diagnosed severe corneal ulcer. 14(58\%) are farmers. Depression was found 58\% before surgery, $70 \%, 62 \%$ and $37.5 \%$ at 1 st, 7 th and 90 th day post operation. 6 patients $(25 \%)$ were classified as severe depression at 1 st and 7 th day post operation. Mean KKU DI score $=7.58(\mathrm{SD}=5.26)$ before surgery, 10.17( $\mathrm{SD}=7.19), 10.27(\mathrm{SD}=8.45)$ and $7.94(\mathrm{SD}=6.91)$ at 1st, 7 th and 90th day post operation. Mean difference score was $2.58(95 \% \mathrm{CI}=0.43,4.74), 2.61(95 \% \mathrm{CI}=0.38,4.83)$ and $-0.46(95 \% \mathrm{CI}=-2.89,1.96)$ at 1 st, 7 th and 90 th day post operation. Mean Health Utility index is 0.80 (range $0.30-1.00)$.
\end{abstract}

Conclusion: There is strong relationship between depression and timing after operation especially in the first day post operation. However, depression was decrease after 90th days post operation. Severity of depression was also decreased by times. This study raise possibility to help the patients' psychological support.

\section{Introduction}

Eye is important organs that affected psychological and mental. Destructive eye surgeries including evisceration and enucleation are necessary for treatment in infection, trauma and tumor. In Thailand there are 1 from 7 people disable from loss of vision in 1996 [1]. Many studies found that they also have a depression. 1 in 3 years Srinagarind hospital has 123 patients with destructive eye surgeries from 20122014. Patient without the eyes might have reduction of quality of life. This report aware of the importance of psychological support for these patients and aim to find the incidence of depression and study about their quality of life.

\section{Materials and methods}

These studies was approved by Khon Kaen University Ethics Committee in human research [HE591074] during June 2016 - January 2017,24 patients were schedule to have evisceration and enucleation in Srinagarind hospital, inform consent was obtained from individual patient.

The 3 parts of questionnaire were obtained.

First part, collecting general information and patient sociodermographic characteristic such as ages, sex, occupation, salary, number of family, indication for surgeries.

Second part, KKUDI questionnaire [Khon Kaen University depression inventory] was obtained during in pre and post operation day $0,1^{\text {st }}, 7^{\text {th }}$, and $90^{\text {th }}$ days. The questionnaire contains 14 questions about depression and the point relative to severity of depression,5-12 points indicate mild depression in men and 6-12 points indicate mild depression in woman,13-14 points indicate moderate depression and morethan or equal 15 points indicate severe depression.

The last questionaire, EuroQol five dimensional questionnaire [2] was obtained as follow; mobility, daily activities and self-care, psychological function, social and role performance, and pain or other health problem for measuring generic health status pre and post operation day 0 and $90^{\text {th }}$. The information was kept secret and didn't label the patient's name. Generalized estimating equation was used to analysed mean different of depression score.

\section{Result}

Median age is 60 years[Q1-Q3,53-70],5 patients [20\%] has underlying diabetic mellitus. Mean salary was 6090 bath [0-50,000]. Other demographic data was shown in Table 1. KKU DI score was shown in Table 2. Mean different of depression score was shown in Table 3. Mean Health Utility index is 0.8 [range 0.3-1.0].

${ }^{\star}$ Correspondence to: Jirathip Luangrungrot, Department of Ophthalmology, Faculty of Medicine, Khon Kaen University, Thailand, E-mail: kae_jl@hotmail.com

Received: May 18, 2018; Accepted: May 25, 2018; Published: June 04, 2018 
Table 1. Demographic data

\begin{tabular}{|c|c|}
\hline Patient characteristic & Number of patient (\%) \\
\hline $\begin{array}{l}\text { Sex } \\
\text { - female } \\
\text { - male }\end{array}$ & $\begin{array}{l}8(33.33 \%) \\
16(66.67 \%)\end{array}$ \\
\hline $\begin{array}{l}\text { Status } \\
\text { - married } \\
\text { - single }\end{array}$ & $\begin{array}{l}21(87.5 \%) \\
3(12.5 \%)\end{array}$ \\
\hline $\begin{array}{l}\text { Occupation } \\
\text { - argriculture } \\
\text { - non agriculture }\end{array}$ & $\begin{array}{l}14(58.33 \%) \\
10(41.67 \%)\end{array}$ \\
\hline $\begin{array}{l}\text { Indication for surgery } \\
\text { - infection } \\
\text { - suprachoroidal haemorrhage } \\
\text { - traumatic endophthalmits }\end{array}$ & $\begin{array}{l}20(83.33 \%) \\
1(4.17 \%) \\
3(12.50 \%)\end{array}$ \\
\hline
\end{tabular}

Table 2. KKUDI Score: number of patients had depression in $0,1^{\text {st }}, 7^{\text {th }}, 90^{\text {th }}$ day post operation.

\begin{tabular}{|c|c|c|c|}
\hline $\begin{array}{c}\text { Number of patient [\%] } \\
\text { Days after surgery }\end{array}$ & Mild depression & Moderate depression & Severe depression \\
\hline day 0 & $9(64.3 \%)$ & $2(14.3 \%)$ & $3(21.4 \%)$ \\
\hline${\text { day } 1^{\text {st }}}^{\text {day } 7^{\text {th }}}$ & $9(52.9 \%)$ & $2(11.8 \%)$ & $6(35.3 \%)$ \\
\hline${\text { day } 90^{\text {th }}}$ & $7(46.7 \%)$ & $2(13.3 \%)$ & $14(64.29 \%)$ \\
\hline
\end{tabular}

Table 3. KKU DI Score: number of patients, mean, SD, mean difference, $95 \%$ CI

\begin{tabular}{|c|c|c|c|c|}
\hline $\begin{array}{c}\text { KKU DI Scores } \\
\text { Days after surgery }\end{array}$ & Number of patient & Mean & SD & Mean difference \\
\hline base line & 24 & 7.58 & 5.26 & 0 \\
\hline day $1^{\text {st }}$ & 24 & 10.17 & 7.19 & 2.58 \\
\hline day $7^{\text {th }}$ & 22 & 10.27 & 8.45 & 2.61 \\
\hline day $90^{\text {th }}$ & 17 & 7.94 & 6.91 & $-0.43,4.74$ \\
\hline
\end{tabular}

\section{Discussion}

Loss of vision might effects quality of life.

El shafie et al. [3] found 53\% of patient have depression in $3^{\text {rd }}$ and $6^{\text {th }}$ month after surgery in Egypt, but this study found most depression in $1^{\text {st }}$ and $7^{\text {th }}$ day after surgery so we should realised that the critical time of depression is early in our patients

Juan Ye et al. [4] studied in China has prevalence of depression in prosthesis clinic $13.8 \%$ while this study found depression in 3rd month of surgery $37.5 \%$, our data suggest to further study to find association that more depression in Srinagarind hospital.

The cause of Evisceration in El shafie et al. [3] was from tumor however our study found almost all was from corneal ulcer from agriculture, this should establish a campaign for farmer to realize the important of using goggle while working.

6 patients [25\%] were classified into severe depression at $1^{\text {st }}$ and $7^{\text {th }}$ day post operation which is strong relationship between depression and timing after operation especially in first day post operation. However, depression was decrease after 90 days post operation. Severity of depression was also decrease by times. Our study raise possibility to help the patients' psychological support.

However, health utility was 0.8 means they doesn't affect much in quality of life, as same as Takkaki Kondo et al. [5] however one eye has loss of visual field at least 20-30 degree horizontally [5].

\section{References}

1. National Statistical Office (1996) Number of visual impairments. (Online)

2. Pattanaphesaj J (2014) Health-related quality of life measure (EQ-5D-5L): mesurement propoty testing and its preference-based score in Thai population [Doctoral dissertion] Mahidol University.

3. Shafie El, Shelil TM, Ahmed IK (2014) "Psychological and Quality-of-Life Changes after Removal of the Eye in a Sample of Adult Patients, Egypt, 2013." Middle East Current Psychiatry 21: 152-159.

4. Ye Juan, Lixia Lou, Kai Jin, Yufeng Xu, Xin Ye (2015) "Vision-Related Quality of Life and Appearance Concerns Are Associated with Anxiety and Depression after Eye Enucleation: A Cross-Sectional Study." PLoS ONE 10 [Crossref]

5. Kondo Takaaki, Walter T Tillman, Terry L Schwartz, John V Linberg, J Vernon Odom (2013) "Health Related Quality of Life after Surgical Removal of An Eye." Ophthalmic Plast Reconstr Surg 29: 51-56. [Crossref]

Copyright: (C2018 Luangrungrot J. This is an open-access article distributed under the terms of the Creative Commons Attribution License, which permits unrestricted use, distribution, and reproduction in any medium, provided the original author and source are credited. 